\title{
Analisis Risiko Kecelakaan Lalu Lintas di Jalan Raya Kabupaten Nganjuk Menggunakan Poisson Point Process on a Linear Network
}

\author{
Nurul Kholisatin ${ }^{1 *}$, Achmad Choiruddin ${ }^{1}$ \\ ${ }^{1}$ Department of Statistics, Institut Teknologi Sepuluh Nopember, Surabaya, Indonesia \\ *Corresponding auhtor: nurulkholis07@gmail.com
}

\begin{abstract}
Kecelakaan lalu lintas yang terjadi di Kabupaten Nganjuk dalam rentang waktu 3 tahun terakhir cukup tinggi, tercatat terdapat 2039 kecelakaan dan terdapat 1977 data lokasi kejadian yang tercatat oleh SATLANTAS Kabupaten Nganjuk dimana sebagian besar lokasi kecelakaan tersebar pada jalan arteri primer dan kolektor primer. Kejadian kecelakaan selama tahun tersebut paling sering terjadi pada Bulan Desember, hari Senin dan di jam 09.00 - 10.00 pagi dan 18.00 - 19.00 malam. Jumlah kecelakaan lalu lintas selama 2018 - 2020 yang terjadi pada siang hari ada sebanyak dua kali lipat dibandingkan pada malam hari, selain itu jumlah kecelakaan pada jalan luar kota juga hampir dua kali lipat dari pada jalan dalam kota.. Kedua kovariat kategorik yang digunakan dijadikan sebagai marks dan masing-masing dimodelkan menggunakan model Poisson Point Process on a Linear Network. Model dengan kovariat waktu kejadian menghasilkan nilai estimasi dari intensitas kecelakaan lalu lintas di siang hari yang $62,3 \%$ lebih tinggi dibandingkan dengan intensitas kecelakaan lalu lintas pada malam hari. Sedangkan, untuk model menggunakan kovariat jenis jalan, dapat diinterpretasikan bahwa intensitas kecelakaan pada jalan luar kota dua kali lipat lebih tinggi dibandingkan dengan intensitas kecelakaan lalu lintas pada jalan dalam kota. Hasil yang didapatkan, model dengan kovariat jenis jalan menghasilkan nilai AIC yang lebih kecil.
\end{abstract}

Keywords- Intensitas, Kecelakaan Lalu Lintas, Kovariat, Point Process on Linear Network, Poisson Point Network.

\section{PENDAHULUAN}

Kecelakaan lalu lintas di jalan raya merupakan penyumbang angka kematian terbesar di dunia. Pada tahun 2002, kecelakaan lalu lintas merupakan penyebab kematian urutan kesebelas di seluruh dunia [1]. Kecelakaan lalu lintas dapat diakibatkan oleh banyak hal, beberapa faktor diantaranya adalah faktor manusia (host), faktor kendaraan (agent) dan faktor lingkungan (enviroment). Faktor manusia sering dianggap sebagai penyebab utama terjadinya kecelakaan. Namun, faktor lingkungan seharusnya dapat menjadi salah satu faktor yang dapat dikendalikan untuk meminimalisir resiko terjadinya kecelakaan lalu lintas.

Kabupaten Nganjuk secara geografis berbatasan dengan Kabupaten Bojonegoro di sebelah utara, Kabupaten Kediri dan Trenggalek di sebelah selatan, di bagian timur dan barat berbatasan dengan Kabupaten Jombang dan Kediri, serta Kabupaten Ponorogo [2]. Posisi Kabupaten Nganjuk berada di antara kota-kota besar menjadikan jalan raya yang ada di Kabupaten Nganjuk memiliki kepadatan yang cukup tinggi. Kondisi di jalan seperti kepadatan lalu lintas juga turut memicu bertambahnya resiko terjadinya kecelakaan lalu lintas. Kabupaten Nganjuk tercatat sebagai kabupaten/kota dengan tingkat kecelakaan nomor dua di Jawa Timur pada tahun 2017 [3]. Data terkini mencatat jumlah kecelakaan yang terjadi di Kabupaten Nganjuk dalam tiga tahun terakhir (2018-2020) ada sebanyak 2.039 kejadian yang tersebar di seluruh wilayah Kabupaten Nganjuk, dengan jumlah korban meninggal dunia sebanyak 526 orang, korban luka berat 61 orang dan korban luka ringan sebanyak 4.064 orang, serta kerugian materiil mencapai Rp3.449.100.000,- [4]. Angka kecelakaan tersebut adalah angka kecelakaan yang tercatat saja (reported accidents), kenyataanya bisa melebihi dari angka kecelakaan tersebut, karena pada kenyataannya masyarakat kadang enggan melaporkan kejadian kecelakaan tersebut pada pihak yang berwenang. Dari data tersebut maka diperlukan adanya upaya untuk mengurangi jumlah kecelakaan. Beberapa upaya yang telah dilakukan untuk mengurangi kecelakaan diantaranya adalah penjagaan oleh polisi di wilayah yang menjadi lokasi rawan lalu lintas dan pemberian rambu lalu lintas untuk sebagai tindakan preventif terjadinya kecelakaan. Pengoptimalan tindakan preventif terjadinya kecelakaan dapat dilakukan analisis mengenai faktor-faktor lingkungan pada lokasi kecelakaan.

Beberapa penelitian yang menggunakan analisis data count hanya dapat menganalisis mengenai faktor penyebab kecelakaan secara umum tanpa memperhatikan kemungkinan bahwa di setiap daerah akan memiliki risiko kecelakaan yang berbeda. Oleh karena itu, pemilihan metode spasial pada penelitian ini diharapkan dapat mengatasi hal tersebut. Beberapa penelitian mengenai kecelakaan lalu lintas yang menggunakan analisis spasial yang telah dilakukan adalah 
analisis pola kecelakaan lalu lintas spasial dan temporal (spatiotemporal) dan untuk mengaturnya sesuai dengan tingkat signifikansinya. Pola spatiotemporal kecelakaan lalu lintas dianalisis menggunakan kernel density estimation (KDE) selama empat musim berbeda [5]. Analisis kecelakaan lalu lintas di Shenzhen, Tiongkok menggunakan metode Geopraphical detection menunjukkan bahwa terdapat heterogenitas stratifikasi spasial dan faktor penyebab keparahan kecelakaan yang berbeda tergantung pada zona/lokasi dan perbedaan waktu kejadian [6]. Serta, jurnal review menyebutkan bahwa dalam analisis point pattern pada jaringan linier memiliki kendala yang beberapa diantaranya adalah perlunya analisis spasial, memperhitungkan jaringan, analisis secara lokal serta ruang dan waktu [7].

Berdasarkan penelitian-penelitian tersebut, pada penelitian ini digunakan waktu terjadinya kecelakaan dan jenis jalan kovariat. Pada penelitian ini akan dilakukan analisis lebih lanjut dari sekedar analisis secara eksak mengenai jumlah kecelakaan lalu lintas di suatu wilayah dan penyebab utama terjadinya kecelakaan. Data yang digunakan berupa data koordinat lokasi kecelakaan beserta data kovariat lainnya, data semacam ini merupakan data spatial point pattern. Analisis pada penelitian ini dilakukan terhadap lokasi kecelakaan lalu lintas di Kabupaten Nganjuk yang dikaitkan dengan beberapa kovariat seperti waktu kejadian dan jenis jalan menggunakan model Poisson point process on linear network.

\section{TINJAUAN PUSTAKA}

\section{A. Spatial Point Process}

Spatial point process berguna sebagai model statistik pola titik yang diamati, di mana titik-titik tersebut mewakili lokasi beberapa objek penelitian. Spatial point process $\mathbf{X}$ adalah mekanisme acak yang hasilnya adalah point pattern. Spatial point pattern $\mathbf{X}$ adalah dataset yang berisi himpunan lokasi objek atau kejadian yang berada pada suatu jendela pengamatan tertentu di sekitar lokasi $u \in L$ dan pada window $B, B \subset L$ yang ditulis $\mathbf{X}=\left\{x_{1}, \ldots, x_{n}\right\}$, dengan $N(\mathbf{X} \cap B)=n$ adalah jumlat titik di $B$ [8] [9].

\section{1) Jaringan Linier}

Ruas garis dengan titik $u$ dan $v$ sebagai ujungnya, memiliki notasi sebagai $[u, v]=\{t v+(1-t) u: 0 \leq t \leq 1\}$. Jaringan linier $L$ merupakan gabungan dari $L=\bigcup_{t=1}^{n} \ell_{t}$ dari ruas garis $\ell_{1}, \ell_{2}, \ldots, \ell_{n}$. panjang total ruas garis pada $L$ dinotasikan sebagai $|L|$. Jalur antara dua titik $u$ dan $v$ pada jaringan linier $L$ merupakan barisan $x_{0}, x_{1}, \ldots, x_{m}$ dari titik di $L$ dimana $x_{0}=u, x_{m}=v$ dan $\left[x_{t}, x_{t+1}\right] \subset L$ untuk setiap $t=0, \ldots, \mathrm{m}-1$. Panjang jalur $x_{0}, x_{1}, \ldots, x_{m}$ didefinisikan dengan $\sum_{t=0}^{m-1}\left\|x_{t+1}-x_{t}\right\|$ dimana \|. || merupakan jarak euclidean. Jarak jalur terpendek (shortest pasth distance) $d_{L}(u, v)$ antara $u$ dan $v$ pada $L$ merupakan jarak minimum seluruh jalur dari $u$ ke $v$. Jika tidak terdapat jalur dari $u$ ke $v$ (menunjukkan bahwa jalur tidak terhubung) maka didefinisikan $d_{L}(u, v)=\infty$ [7][10].

\section{2) Intensitas}

Intensitas adalah karakteristik deskriptif dasar dari suatu point process yang merupakan ekspektasi atau firstorder moment properties [7] [9]. Intensitas adalah densitas rata-rata titik (jumlah titik yang diharapkan per unit panjang. Ekspektasi jumlah titik yang diamati pada observation window $B$ ditunjukkan pada persamaan 1 .

$$
\mu(B)=E\left[N_{\mathbf{x}}(B)\right]=\int_{B} \lambda(\boldsymbol{u}) d \boldsymbol{u}, B \subseteq L
$$

Fungsi intensitas $\lambda(\boldsymbol{u})$ dari point process $\mathbf{X}$ yang merupakan peluang mengobservasi sebuah titik di suatu jendela pengamatan tertentu di sekitar lokasi [8]. Intensitas dapat bernilai konstan (homogen) atau bervariasi spasial (tidak homogen). Ketika intensitasnya bervariasi secara spasial, intensitas berperan menjadi fungsi spasial yang salah satunya dipengaruhi oleh kovariat spasial $z(\boldsymbol{u})$. Intensitas dapat dimodelkan dalam bentuk model parametrik log-linear sesuai dengan persamaan 2 dengan $\boldsymbol{\beta}$ adalah parameter yang diestimasi.

$$
\lambda(\boldsymbol{u})=\lambda(\boldsymbol{u} ; \boldsymbol{\beta})=\exp \left(\boldsymbol{\beta}^{T} \mathbf{z}(\mathbf{u})\right)
$$

Pada setiap lokasi spasial $\boldsymbol{u}$, misalkan $\lambda(\boldsymbol{u})$ merupakan intensitas point process yang hanya bergantung dari nilai dari kovariat $z(\boldsymbol{u})$, maka dapat diasumsikan $\lambda(\boldsymbol{u})=\rho(z(\boldsymbol{u}))$, dimana $\rho$ adalah fungsi yang menunjukkan intensitas points bergantung pada nilai kovariat. Jika intensitas di suatu lokasi $\boldsymbol{u}$ tidak bergantung pada nilai kovariat $z(\boldsymbol{u}), \hat{\rho}(z)$ adalah estimasi dari rata-rata intensitas $\lambda(\boldsymbol{u})$ di semua lokasi $\boldsymbol{u}$ di mana $z(\boldsymbol{u})=z$. $\rho$ dapat diestimasi secara parameterik maupun nonparametrik [9]. 


\section{B. Poisson Point Process on a Linear Network}

Point pattern on linear network merupakan pola spasial dari titik yang tersebar pada suatu jaringan garis (network of lines), contohnya pola kecelakaan lalu lintas pada jalan raya, pola kejahatan yang terjadi di suatu area, dan pola persebaran sarang laba-laba pada sekat di dinding.

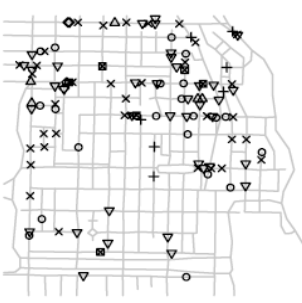

(a)

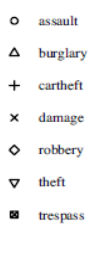

$\nabla$ theft

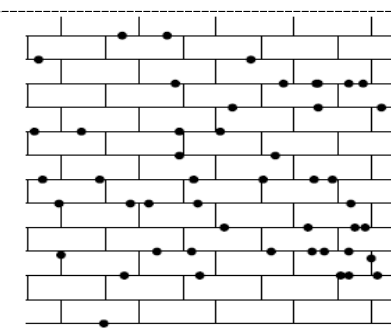

(b)

Gambar 1 (a) Data Chicago Crimes. Lokasi dan Tipe dari 116 kejahatan yang tercatat di sekitar University of Chicago selama 2 minggu pada 2002. (b) Sarang laba-laba pada sekat dinding. Tersedia pada spatstat package sebagai spiders dataset.

Poisson point process dikatakan homogen apabila intensitas bernilai konstan. Sedangkan, Inhomogeneous Poisson process merupakan suatu proses Poisson dengan fungsi intensitas atau rata-rata proses yang tidak konstan dan bervariasi dalam ruang atau waktu. Inhomogeneous Poisson process dengan fungsi intensitas $\lambda(u)$ bergantung pada parameter $u$. Point process $\mathbf{X}$ pada jaringan linier dapat dikatakan sebagai inhomogeneous Poisson process, dengan intensitas $\lambda(u) \geq 0$, jika memenuhi karakteristik untuk inhomogeneous Poisson process [9]. Pada point pattern on linear network, model Poisson point process dapat dirumuskan seperti halnya pada point pattern dua dimensi. Diasumsikan bahwa intensitas (titik per unit panjang) memiliki bentuk loglinier [8] [11][12].

$$
\lambda_{\theta}(u)=\exp \left(\boldsymbol{\theta}^{\mathrm{T}} \mathbf{Z}(u)\right)
$$

dimana $\mathbf{Z}(u)$ merupakan fungsi kovarians spasial dengan nilai numerik atau vektor, dan $\rho$ merupakan parameter vektor.

\section{1) Uji Chi-Square}

Uji Chi-Square dilakukan untuk mengetahui apakah intensitas data point pattern termasuk dalam sebaran pola yang stasioner atau tidak [9], sehingga pada estimasi parameter akan didapatkan model yang sesuai dengan karakteristik persebaran dari data point pattern. Hipotesis dari uji Chi-Square adalah sebagai berikut.

$H_{0}: \mu_{1}=\mu_{2}=\cdots=\mu_{m}$

$H_{1}: \mu_{i} \neq \mu_{j}, \quad i=1,2, \ldots, m ; j=1,2, \ldots, m$

Statistik uji yang digunakan untuk menguji hipotesis di atas yaitu

\section{Estimasi Parameter}

$$
\chi_{\text {hitung }}^{2}=\sum_{j=1}^{m} \frac{(\text { observed }- \text { expected })^{2}}{\text { expected }}=\sum_{j=1}^{m} \frac{\left(n_{j}-e_{j}\right)^{2}}{e_{j}}
$$

Estimasi dilakukan menggunakan pendekatan maximum likelihood untuk $\rho$ pada model Inhomogeneous Poisson Point Process dengan intensitas $\lambda_{\rho}(u)$, Model intensitas point process pada penelitian ini menggunakan model log-linear dengan intensitas $\lambda_{\rho}(u)$ yang bergantung pada parameter $\rho$ untuk diestimasi, dituliskan sebagai berikut

$$
\lambda_{\rho}(u)=\exp (\rho \mathbf{Z}(u)+A(u))
$$

di mana $\mathbf{Z}(u)$ dan $A(u), u \in L$ adalah fungsi yang diketahui. Di sini $\mathbf{Z}(u)$ adalah vektor dari $p$ kovariat spasial yang masing-masing terkait dengan satu komponen vektor parameter $\rho$ berdimensi $p$. Sedangkan fungsi $A(u)$ tidak terikat dengan parameter dan dikenal dengan istilah offset [9].

\section{Uji Kesesuaian Model}

Pemilihan model terbaik akan dilakukan menggunakan Akaike Information Criterion (AIC) dengan persamaan [12].

$$
\mathrm{AIC}=-2 \log L_{\max }+2 p
$$

dengan $L_{\max }=L(\hat{\rho})$ adalah nilai maksimum fungsi likelihood dari model dan $p$ adalah banyaknya parameter dalam model. 


\section{METODOLOGI PENELITIAN}

\section{A. Sumber Data}

Data yang digunakan pada penelitian ini adalah data sekunder berupa koordinat data lokasi kecelakaan lalu lintas di Kabupaten Nganjuk pada 2018-2020 (tanpa data Oktober 2018, September 2019 dan Februari 2020), data jenis jalan lokasi kecelakaan dan waktu terjadinya kecelakaan. Data koordinat lokasi kecelakaan lalu lintas, jenis jalan lokasi kecelakaan dan waktu kejadian yang digunakan didapatkan dari Satlantas Kabupaten Nganjuk.

\section{B. Variabel Penelitian}

Variabel penelitian yang digunakan dalam penelitian ini disajikan pada Tabel 1.

\begin{tabular}{clll}
\multicolumn{4}{c}{ Tabel 1 Variabel Penelitian } \\
\hline Variabel & \multicolumn{1}{c}{ Keterangan } & \multicolumn{1}{c}{ Label/Skala } \\
\hline \multirow{2}{*}{ X } & $\begin{array}{l}\text { Himpunan lokasi kecelakaan } \\
\text { lalu lintas di Kabupaten }\end{array}$ & Derajat Koordinat \\
& Nganjuk & & \\
\multirow{2}{*}{$Z_{1}$} & Jenis jalan lokasi kecelakaan & Siang : 06.00 - 18.00 & 0 \\
& & Malam : 18.00 - 06.00 & 1 \\
$Z_{2}$ & Usia pertama pacaran & Jalan luar kota (lain) & 0 \\
& & Jalan dalam kota & 1 \\
& & (lokal) & \\
\hline
\end{tabular}

\section{Langkah Analisis}

Langkah-langkah yang dilakukan dalam penelitian kali ini yaitu :

1. Merumuskan latar belakang dan masalah penelitian.

2. Melakukan studi literatur dan referensi terkait analisis spasial untuk kasus kecelakaan lalu lintas.

3. Mengumpulkan data koordinat lokasi kecelakaan.

4. Mengumpulkan covariates dan melakukan transformasi covariates.

5. Pre-processing data.

6. Menentukan observation window.

7. Melakukan analisis eksplorasi data dengan mengidentifikasi data untuk mengetahui korelasi spasial data dengan mengidentifikasi homogenitas / stasioner data dengan uji Chi-squared.

8. Melakukan estimasi parameter model menggunakan pendekatan maximum likelihood.

9. Membentuk model intensitas kecelakaan lalu lintas dengan kovariatnya menggunakan Poisson point process.

10. Menguji kebaikan model menggunakan AIC.

11. Menarik kesimpulan dan saran.

\section{ANALISIS DAN PEMBAHASAN}

A. Karakteristik Persebaran_Lokasi Kecelakaan_di Kabupaten Nganjuk_Tahun 2018-2020

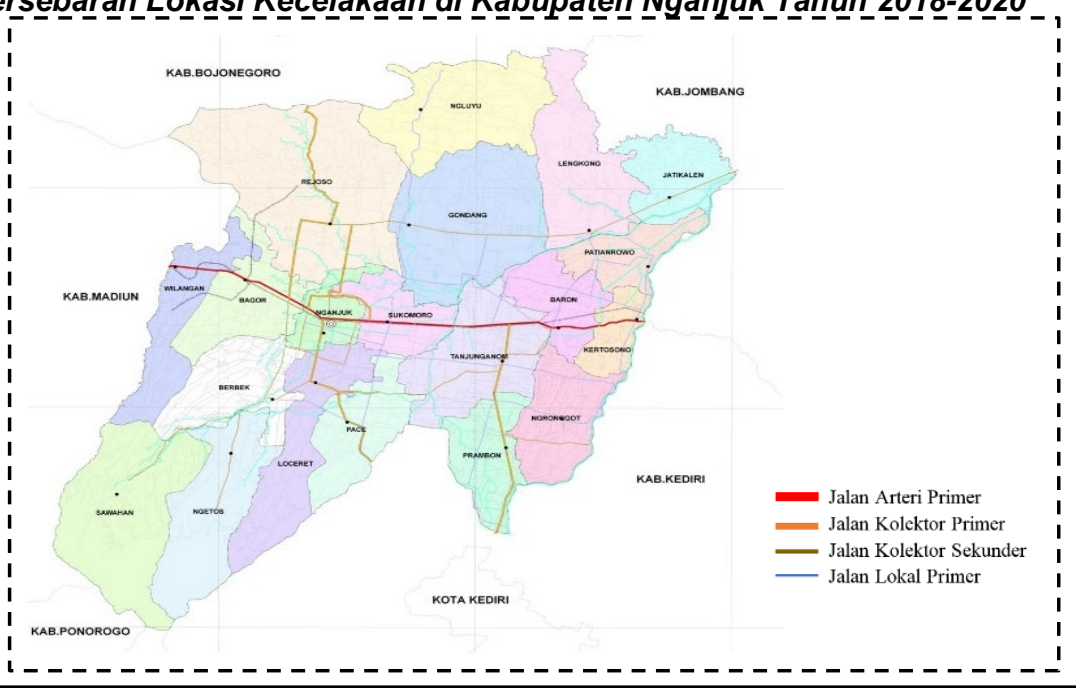

Gambar 2 Peta Jaringan Jalan di Kabupaten Nganjuk (Sumber : RTRW Kab. Nganjuk 2010 - 2030) 


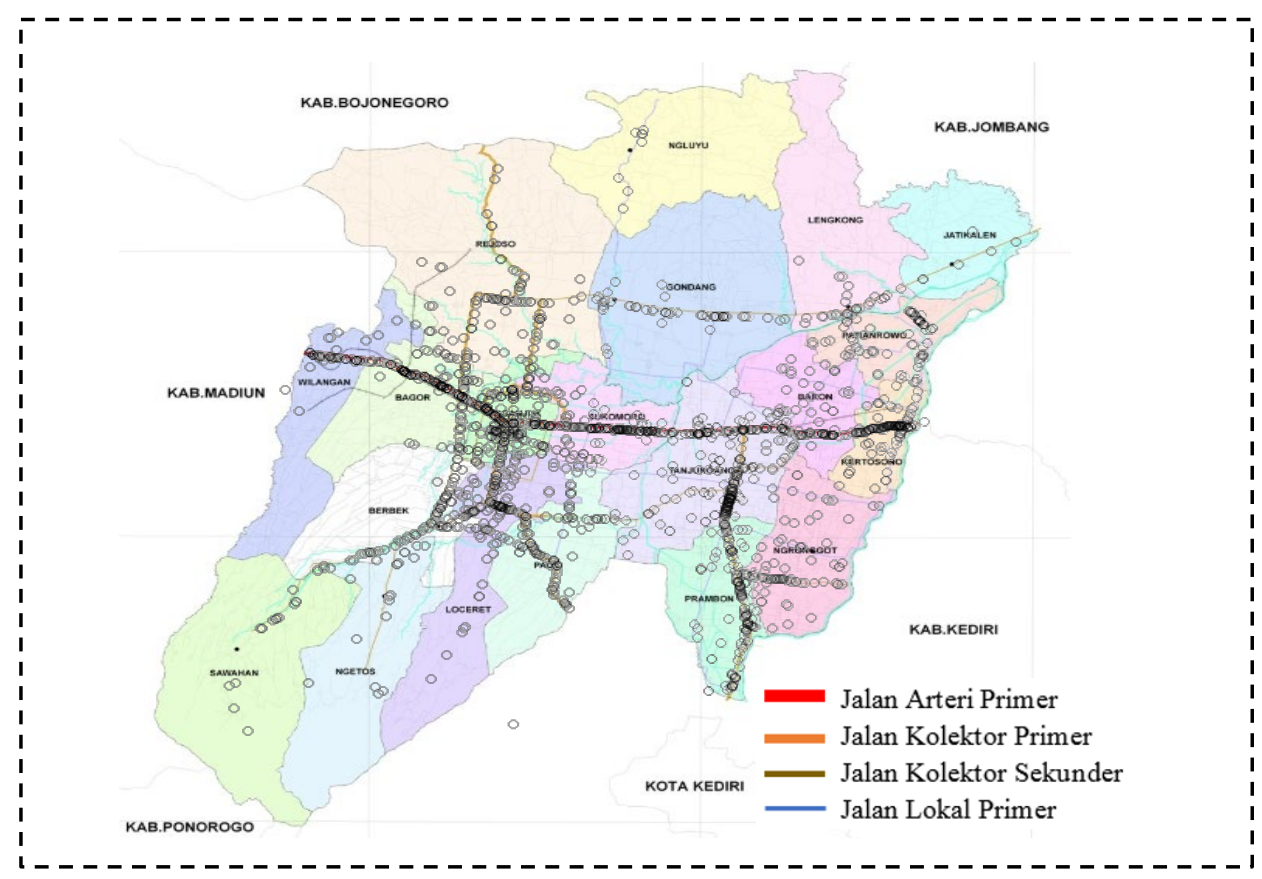

Gambar 3 Peta Persebaran Lokasi Kecelakaan Kendaraan Bermotor di Jalan Raya Kabupaten

Gambar 2 menunjukkan peta jaringan jalan di Kabupaten Nganjuk yang bersumber dari Rencana Wilayah Tata Ruang Wilayah (RTRW) Kabupaten Nganjuk tahun 2010-2030 yang terdiri dari empat jenis jalan yakni, Jalan Arteri Primer, Jalan Kolektor Primer, Jalan Kolektor Sekunder, dan Jalan Lokal Primer. Warna-warna dari setiap area pada Gambar 2 menunjukkan area setiap kecamatan, juga dimaksudkan untuk memudahkan interpretasi dari persebaran titik lokasi kecelakaan lalu lintas di Kabupaten Nganjuk namun fokusan interpretasi terletak pada jenis jalan yang ada karena pada penelitian ini digunakan jenis jalan yang berbeda, yakni dua jenis jalan, jalan/jalur dalam kota (lokal) dan jalan/jalur luar kota (lain) sesuai dengan yang digunakan dalam data laporan kecelakaan dari SATLANTAS Kabupaten Nganjuk. Data laporan kejadian kecelakaan lalu lintas dari SATLANTAS Kabupaten Nganjuk selama 2018 - 2020 telah mencatat adanya 2.039 kejadian yang tersebar di seluruh wilayah Kabupaten Nganjuk. Gambar 3 menunjukkan peta jaringan jalan di Kabupaten Nganjuk yang terdiri dari empat jenis jalan yakni, Jalan Arteri Primer, Jalan Kolektor Primer, Jalan Kolektor Sekunder, dan Jalan Lokal Primer. Warna-warna dari setiap area pada Gambar 3 menunjukkan area setiap kecamatan, juga dimaksudkan untuk memudahkan interpretasi dari persebaran titik lokasi kecelakaan lalu lintas di Kabupaten Nganjuk namun fokusan interpretasi terletak pada jenis jalan yang ada karena pada penelitian ini digunakan jenis jalan yang berbeda, yakni dua jenis jalan, jalan/jalur dalam kota (lokal) dan jalan/jalur luar kota (lain) sesuai dengan yang digunakan dalam data laporan kecelakaan dari SATLANTAS Kabupaten Nganjuk. Persebaran lokasi kecelakaan di Kabupaten Nganjuk secara visual jalur arteri yang melintasi Kecamatan Nganjuk, Kecamatan Bagor, Kecamatan Sukomoro serta Kecamatan Kertosono merupakan bagian dari jalur arteri yang memiliki intensitas kecelakaan yang paling tinggi selama tahun 2018-2020. Selain pada ruas jalan arteri primer, titik lokasi kecelakaan juga cukup banyak tersebar di ruas jalan kolektor primer pada ruas jalan kolektor primer di Kecamatan Tanjung Anom, pada ruas jalan yang berdekatan dengan perbatasan Kecamatan Prambon.

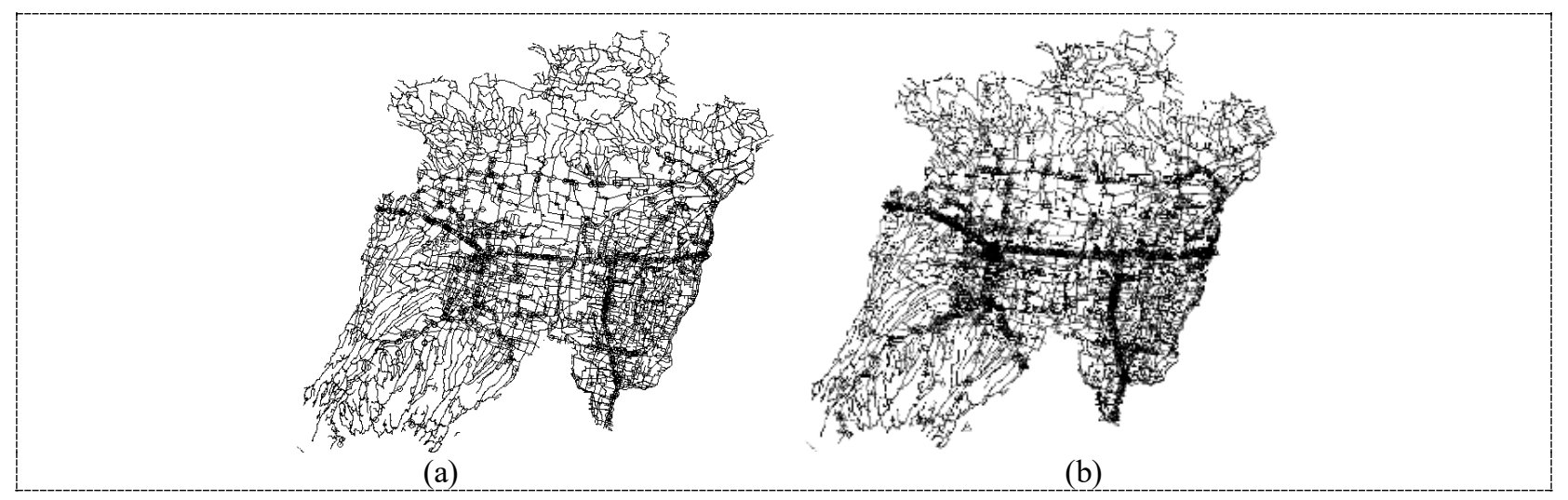

Gambar 4 (a) Sebaran Lokasi Kecelakaan di Jalan Raya Kabupaten Nganjuk pada Malam hari, (b) Sebaran Lokasi Kecelakaan di Jalan Rava Kabunaten Naaniuk bada Siana hari 
Gambar 4 (a) menunjukkan sebaran lokasi kecelakaan pada waktu malam hari, tercatat terdapat 738 titik lokasi kecelakaan yang terjadi pada malam hari. Jika dilihat secara visual terlihat bahwa pada malam hari ruas jalan yang memiliki jumlah kecelakaan lalu lintas yang tinggi berada pada ruas jalan di Kecamatan Kertosono yang berdekatan dengan perbatasan Kabupaten Kediri dan Kabupaten Jombang, ruas jalan arteri primer di Kecamatan Nganjuk, juga Kecamatan Bagor, serta sepanjang ruas kolektor primer di Kecamatan Tanjung Anom hingga Kecamatan Prambon. Sebaran titik lokasi kecelakaan pada malam hari di ruas jalan kolektor sekunder sepanjang Kecamatan Rejoso, Kecamatan Gondang, Kecamatan Lengkong, hingga Kecamatan Jatikalen terhitung sedikit dan hanya terjadi pada persimpangan jalan tertentu.

Gambar 4 (b) menunjukkan sebaran titik lokasi kecelakaan di siang hari hampir mencapai dua kali lipat dari pada kecelakaan yang terjadi pada malam hari yakni sebanyak 1206 kecelakaan. Lokasi kecelakaan pada kedua waktu tersebut mayoritas terjadi di lokasi-lokasi yang serupa.

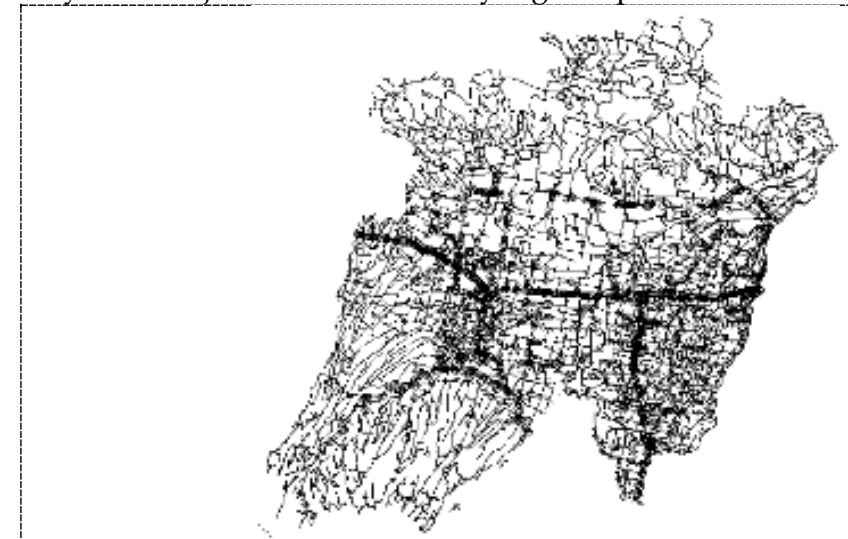

(a)

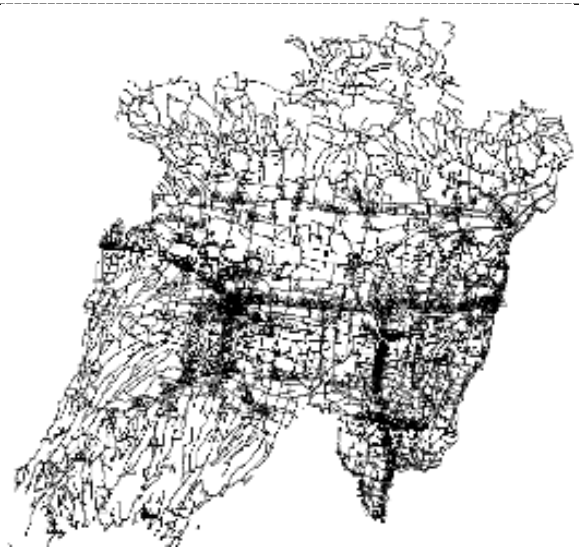

(b)

Gambar 5 (a) Sebaran Lokasi Kecelakaan di Jalan Raya Kabupaten Nganjuk pada Jalan Luar Kota (Lain), (b) Sebaran Lokasi Kecelakaan di Jalan Rava Kabunaten Naaniuk bada Jalan Dalam Kota (Lokal)

Gambar 5 (a) menunjukkan sebaran lokasi kecelakaan secara visual terlihat bahwa di jalan luar kota (lain) memiliki jumlah titik kecelakaan sebanyak 1276 titik kecelakaan. Titik-titik lokasi kecelakaan yang padat juga terdapat pada jalur arteri utama sepanjang Kecamatan Wilangan yang berbatasan dengan Kabupaten Madiun hingga Kecamatan Kertosono yang berbatasan dengan Kabupaten Kediri dan Kabupaten Jombang. Juga ruas kolektor utama maupun sekunder di Kecamatan Nganjuk, Kecamatan Tanjung Anom hingga Kecamatan Prambon, kemudian pada ruas lokal primer, titiktitik lokasi kecelakaan terlihat tersebar di sekitar Kecamatan Ngronggot.

Sebaran titik lokasi kecelakaan yang terjadi pada jalan dalam kota ditunjukkan oleh Gambar 5 (b) dimana jumlah titik kecelakaan yang terjadi ada sebanyak 668 titik kecelakaan, nilainya hampir setengah dari jumlah titik kecelakaan pada jalan luar kota. Secara visual, sebaran titik lokasi kecelakaan pada ruas arteri primer di Kecamatan Wilangan dan Kecamatan Bagor tidak begitu padat jika dibandingkan dengan Gambar 5 (a). Hal yang sama juga terjadi untuk ruas lokal primer di wilayah Kecamatan Ngronggot.

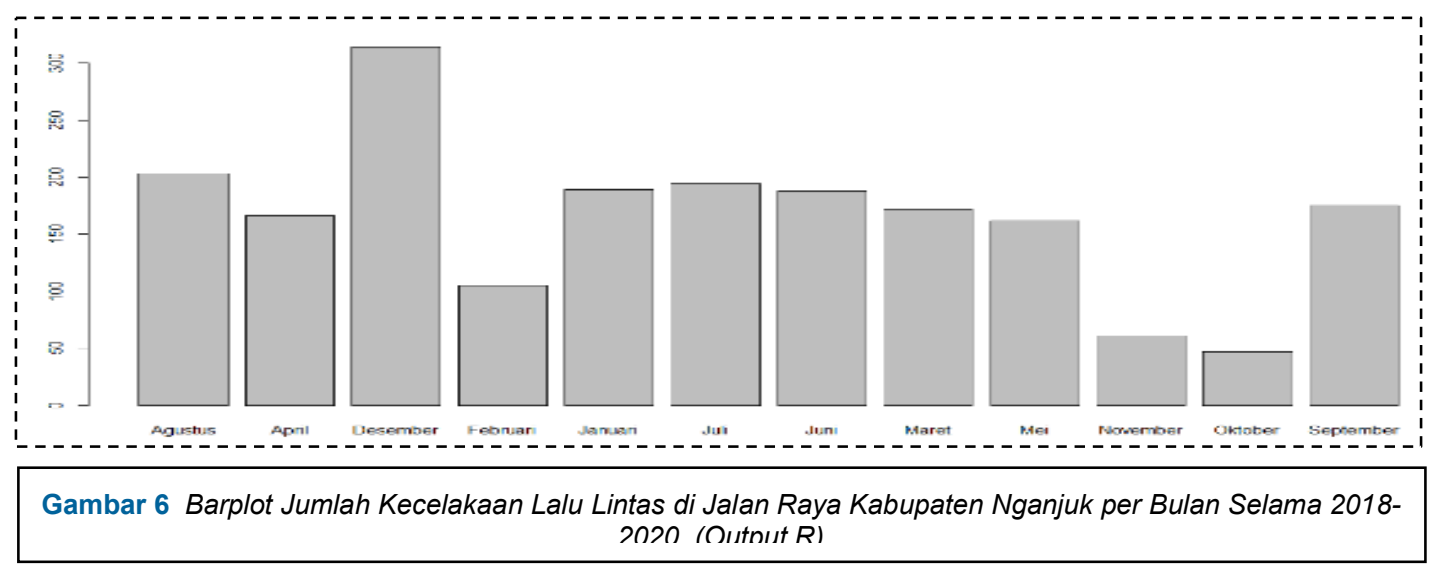

Gambar 6 menunjukkan akumulasi jumlah kecelakaan pada setiap bulannya selama 2018-2020 yang menunjukkan bahwa kecelakaan lalu lintas paling sering terjadi pada Bulan Desember pada 3 tahun tersebut, sedangkan yang paling rendah atau paling jarang terjadi pada Bulan Oktober. 


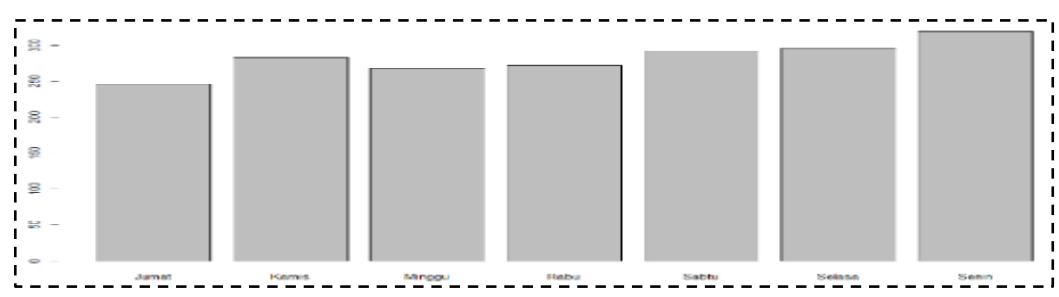

Gambar 7 Barplot Jumlah Kecelakaan Lalu Lintas di Jalan Raya Kabupaten Nganjuk per Hari Selama 2018-2020. (Output R)

Gambar 7 menunjukkan akumulasi jumlah kecelakaan yang terjadi di Jalan Raya Kabupaten Nganjuk selama 2018 2020 pada setiap harinya. Jumlah kecelakaan lalu lintas per harinya tidak begitu berbeda, berkisar pada 250 hingga 300 kecelakaan. Hari Senin adalah hari yang memiliki jumlah kecelakaan paling tinggi selama 2018 - 2020 dan Jumat adalah yang paling rendah.

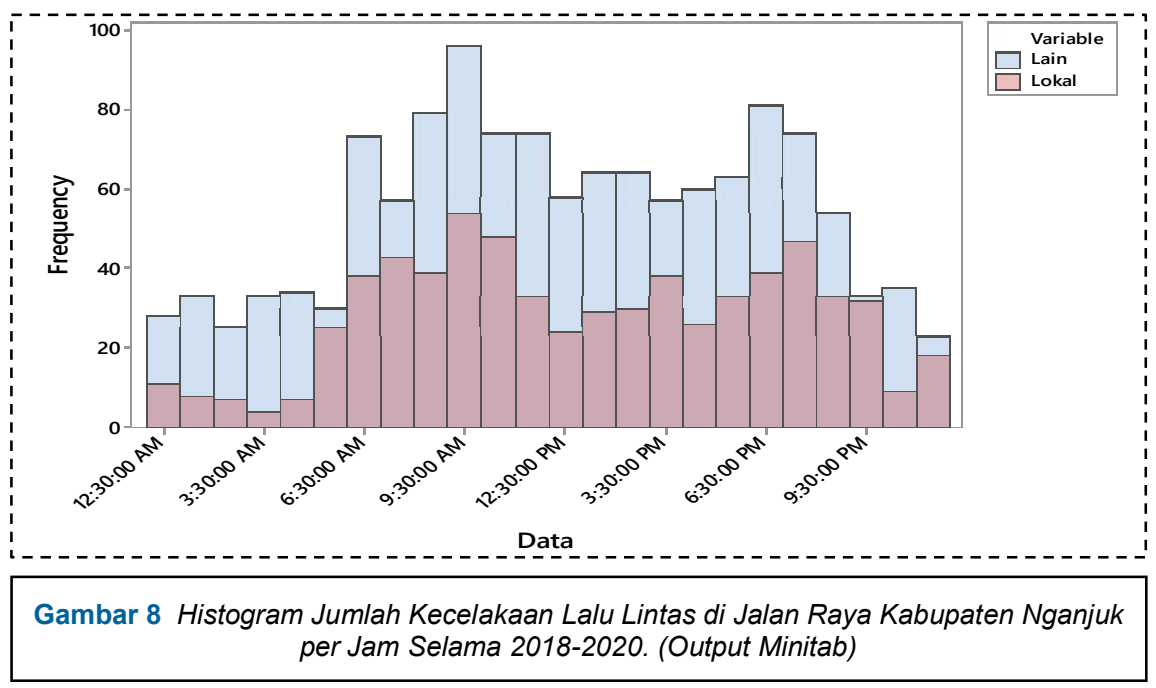

Gambar 8 menunjukkan bahwa waktu-waktu yang memiliki jumlah kecelakaan yang tinggi selama tiga tahun tersebut adalah sekitar jam 09.30 hingga 10.00 pagi dan jam 18.30 hingga 19.30 malam, sedangkan yang paling rendah adalah sekitar jam 21.00 hingga 06.00 pagi.

\section{B. Pemodelan Analisis Risiko Kecelakaan menggunakan Poisson Point Process on Linear Network}

Sebelum melakukan pemodelan menggunakan Poisson point process perlu dilakukan uji chi-squared pada data untuk mengetahui apakah sebaran titik bervariasi spasial atau tidak.

\section{1) Uji Chi-Squared}

Pengujian homogenitas menggunakan uji chi-squared ini dilakukan seperti pengujian homogenitas untuk point pattern dua dimensi, oleh karena itu dilakukan pembagian observation window menjadi beberapa area grid. Pada penelitian ini, observation window dibagi kedalam grid ukuran $5 \times 5$. Hasil Chi-Squared hitung yang didapatkan sebesar $\chi_{\text {hitung }}^{2}=3488,7$ dengan $d f=24$, nilai tersebut lebih besar dibandingkan dengan nilai Chi-Squared tabel dengan alpha 0,05 dan $d f 24$ yang sebesar 37,562, sehingga berdasarkan hipotesis pada subbab 2.2.1 menghasilkan keputusan tolak $\mathrm{H}_{0}$. Pvalue hasil uji Chi-Squared juga bernilai $<0,05$ sehingga menghasilkan keputusan bahwa pada taraf signifikansi $5 \%$ adalah tolak Ho. yang berarti persebaran lokasi kecelakaan di Kabupaten Nganjuk tidak stasioner dan terdapat tren spasial secara signifikan pada persebaran titik lokasi kecelakaan di Kabupaten Nganjuk.

2) Pemodelan Persebaran Lokasi Kecelakaan Menggunakan Poisson Point Process on Linear Network

Hasil uji homogenitas menunjukkan bahwa sebaran titik lokasi kecelakaan memiliki tren spasial yang menunjukkan adanya pengaruh faktor lingkungan pada lokasi terjadinya kecelakaan. Pada penelitian ini akan dibahas faktor waktu terjadinya kecelakaan yang dijadikan dua kategori (siang dan malam) serta jenis jalan yang menjadi titik lokasi kecelakaan yang juga dibedakan menjadi dua kategori (jalan lokal dan jalan lain).

Pemodelan menggunakan Poisson point process dilakukan mengunakan masing-masing kovariat waktu kejadian kecelakaan dan jenis jalan lokasi terjadinya kecelakaan. Kedua kovariat merupakan kovariat kategorik sehingga pada penelitian ini akan diperlakukan sebagai faktor dengan masing-masing memiliki dua level (marks) ${ }^{[8]}$. Level faktor untuk masing-masing kovariat terdiri dari 0 (malam) dan 1 (siang) untuk kovariat waktu dan 0 (lokal) dan 1 (lain) untuk jenis jalan. Level malam dan jalan lokal akan menjadi level standar untuk pembanding level lainnya. 
Sebagai permisalan, jika $z_{1}(u)$ merupakan jenis waktu lokasi kejadian kecelakaan pada sembarang lokasi $u$. Didefinisikan $f_{1}(u)=1\left\{z_{1}(u)=1\right\}$, fungsi indikator akan bernilai sama dengan 1 ketika kondisi waktu kecelakaan terjadi di siang hari, dan sama dengan 0 untuk waktu lainnya. Begitu pula dengan kovariat jenis jalan, jika $z_{2}(u)$ merupakan jenis jalan lokasi kecelakaaan pada sembarang lokasi $u$. Didefinisikan $f_{1}(u)=1\left\{z_{2}(u)=1\right\}$, dimana fungsi indikator akan bernilai sama dengan 1 ketika jenis jalan lokasi kecelakaan merupakan jalan luar kota (lain) dan akan bernilai 0 untuk jenis jalan lainnya.

Estimasi parameter untuk model Poisson point process on linear network dengan kovariat waktu kejaidan ditunjukkan pada Tabel 2.

\begin{tabular}{|c|c|c|c|}
\hline Parameter & Estimasi & $\operatorname{Exp}(\widehat{\rho})$ & Z-value \\
\hline Intercept & -8.612 & $1.818 \times 10^{-4}$ & $-233.9^{* * *}$ \\
\hline $\begin{array}{l}\text { Waktu Kejadian } \\
\text { ( } z_{1}=\text { siang hari) }\end{array}$ & 0.491 & 1.634 & $0.4^{* * *}$ \\
\hline
\end{tabular}

Berdasarkan tabel 2 nilai intercept dan kovariat waktu kejadian berpengaruh signifikan terhadap intensitas terjadinya kecelakaan lalu lintas dengan $\boldsymbol{\alpha}=\mathbf{0 , 0 5}$ nilai $\left|Z_{\text {value }}\right|$ pada kovariat waktu kejadian bernilai lebih dari $Z_{0,025}=1,96$ sehingga model yang terbentuk adalah sebagai berikut

$$
\lambda_{\rho}(u)=\exp \left(-8,6124440+0,4913301 z_{1}(u)\right)
$$

Berdasarkan model yang terbentuk dapat diinterpretasikan bahwa pada siang hari intensitas kecelakaan lalu lintas bernilai 1,634 kali dari pada malam hari atau 0,634 kali lebih berisiko dibandingkan pada malam hari. Sebagai contoh, misalnya dalam suatu lokasi $u$ memiliki volume lalu lintas kendaraan sebesar 1000 AADT (Annual Average Daily Traffic), pada kondisi malam hari, menurut model yang terbentuk nilai ekspektasi terjadinya kecelakaan pada lokasi $u$ adalah sebesar $1000 \times \exp (-8,6124440)=0,1818$ per kilometer. Sebaliknya, dengan kondisi yang sama pada siang hari, menurut model yang terbentuk nilai ekspektasi terjadinya kecelakaan pada lokasi tersebut adalah sebesar $1000 \times \exp (-8,6124440+0,4913301)=0,2972$ per kilometer.

\begin{tabular}{|c|c|c|c|}
\hline Parameter & Estimasi & $\operatorname{Exp}(\widehat{\rho})$ & Z-value \\
\hline Intercept & -8.065 & $3.145 \times 10^{-4}$ & $-288.074^{* * *}$ \\
\hline $\begin{array}{l}\text { Jenis Jalan } \\
\left(z_{2}=\text { lokal }\right)\end{array}$ & -0.648 & 0.523 & $-13.5633^{* * *}$ \\
\hline
\end{tabular}

Berdasarkan Tabel 3 baik intersep maupun kovariat jalan keduanya berpengaruh signifikan terhadap intensitas terjadinya kecelakaan lalu lintas dengan $\alpha=0,05$ nilai $\left|Z_{\text {value }}\right|$ pada kovariat jenis jalan lebih dari $Z_{0,025}=1,96$ sehingga model yang terbentuk dengan kovariat Jenis Jalan sebagai marks adalah sebagai berikut,

$$
\lambda_{\rho}(u)=\exp \left(-8,0645273-0,6477377 z_{2}(u)\right)
$$

Berdasarkan model yang diperoleh dapat diketahui bahwa intensitas terjadinya kecelakaan di jalan dalam kota (lokal) adaah sebesar 0,523 atau dapat dikatakan 52,3\% dari intensitas kecelakaan lalu lintas di jalan luar kota (lain). Dapat pula dikatakan bahwa intensitas kecelakaan pada jalan dalam kota memiliki risiko setengah kali lebih rendah dibandingkan intensitas kecelakaan lalu lintas di jalan luar kota (lain). Sebagai contoh, pada suatu lokasi di jalan luar kota (lain) memiliki volume lalu lintas kendaraan sebesar 1000 AADT maka nilai ekspektasi terjadinya kecelakaan pada lokasi tersebut berdasarkan model sebesar, $1000 \times \exp (-8,0645273)=0,3145$ per kilometer, sedangkan pada kondisi yang sama di jalan dalam kota (lokal) menurut model yang terbentuk akan memiliki nilai ekspektasi terjadi kecelakaan sebesar $1000 \times \exp (-8,0645273-0,6477377)=0,1645$ per kilometer.

\section{3) Kebaikan Model Poisson Point Process}

Kebaikan model Poisson Point Process dalam memodelkan risiko kecelakaan lalu lintas di Kabupaten Nganjuk dapat dilihat dari nilai AIC masing-masing model yang disajikan pada Tabel 4. 
Tabel 4 Estimasi Parameter Poisson Point Pattern dengan Kovariat Jenis Jalan

\begin{tabular}{lc}
\hline Fungsi Intensitas & AIC \\
\hline Log-linier (Waktu Kejadian) & 36192,09 \\
Log-linier (Jenis Jalan) & 36112,26 \\
\hline
\end{tabular}

Tabel 4 menunjukkan bahwa nilai AIC dari kedua kovariat tidak begitu berbeda, namun nilai AIC yang terkecil dari model Poisson Point Process terdapat pada fungsi intensitas menggunakan log-linier dengan kovariat jenis jalan yaitu 36112,26 .

\section{KESIMPULAN DAN SARAN}

Kesimpulan yang diperoleh berdasarkan analisis dan pembahasan adalah: pertama, karakteristik persebaran lokasi kecelakaan di Kabupaten Nganjuk selama 2018-2020 sebagian besar menyebar pada jalan arteri primer dan kolektor primer. Jalur arteri yang melintasi Kecamatan Nganjuk, Kecamatan Bagor, Kecamatan Sukomoro serta Kecamatan Kertosono merupakan bagian dari jalur arteri yang memiliki intensitas kecelakaan yang paling tinggi. Selain itu, titik lokasi kecelakaan juga cukup banyak tersebar di ruas jalan kolektor primer. Contohnya, pada ruas jalan kolektor primer di Kecamatan Tanjung Anom, pada ruas jalan yang berdekatan dengan perbatasan Kecamatan Prambon. Sebaran titik lokasi kecelakaan pada siang hari bernilai hampir 2 kali lipat dari pada titik lokasi kecelakaan pada malam hari dan sebaran titik lokasi kecelakaan pada jalan luar kota juga bernilai hampir 2 kali lipat dari sebaran titik lokasi kecelakaan pada jalan dalam kota. Akumulasi jumlah kecelakaan selama 3 tahun tersebut paling sering terjadi pada Bulan Desember dibandingkan bulan lainnya, jika berdasarkan hari, Senin adalah yang tertinggi akumulasi jumlah kecelakaannya, dan berdasarkan waktu kecelakaan (jam) paling sering terjadi pada pukul 9 sampai 10 pagi dan 6 sampai 7 malam. Kedua, sebaran titik lokasi kecelakaan di Kabupaten Nganjuk berdasarkan hasil uji Chi-Squared menunjukkan adanya tren spasial dan pengaruh faktor lingkungan pada lokasi kecelakaan. Berdasarkan model dengan kovariat waktu kejadian, dapat diinterpretasikan bahwa pada siang hari intensitas kecelakaan lalu lintas bernilai 1,634 kali dari pada malam hari atau 0,634 kali lebih berisiko dari pada malam hari. Sedangkan, untuk model dengan kovariat jenis jalan, dapat dikatakan bahwa intensitas kecelakaan pada jalan dalam kota memiliki risiko setengah kali lebih rendah dibandingkan intensitas kecelakaan lalu lintas di jalan luar kota (lain). Pemodelan menggunakan Poisson point process dengan kovariat jenis jalan memiliki AIC yang paling kecil pada analisis risiko kecelakaan lalu lintas di Kabupaten Nganjuk.

Saran yang diberikan pada penelitian selanjutnya mengenai analisis risiko kecelakaan lalu lintas, diantaranya adalah dengan mempertimbangkan penggunaan jenis ruas jalan sesuai dengan yang ada ditetapkan oleh dinas perencanaan tata ruang dan wilayah di Kabupaten Nganjuk, dan multi-type point pattern [13] dapat dipertimbangkan pada analisis berikutnya. Melakukan pengujian homogenitas sebaran titik lokasi kecelakaan (uji Chi-Square) menggunakan acuan uji yang lain. Hal ini sebaiknya dilakukan karena pada pengerjaan penelitian ini, komputasi untuk pengujian homogenitas untuk point pattern pada ruang satu dimensi masih belum dikembangkan, sehingga peneliti menggunakan uji Chi-Squared yang umum digunakan untuk pengujian homogenitas pada point pattern ruang dua dimensi. Melakukan analisis sebaran titik lokasi kecelakaan menggunakan peta yang lebih lengkap dan mendetail, sehingga informasi yang diperoleh dapat lebih banyak dan mempertimbangkan penggunaan model yang dapat memodelkan lebih dari dua kovariat secara langsung, baik kovariat kategorik maupun kovariat numerik.

\section{REFERENSI}

[1] M. Peden, R. Scurfield, D. Sleet, E. Jarawan dan C. Mathers, “Worlds Report on Road Traffic Injury Prevention,” World Health Organization, Geneva, 2004.

[2] Badan Pusat Statistik Kabupaten Nganjuk, Kabupaten Nganjuk Dalam Angka 2020, Nganjuk: Badan Pusat Statistik Kabupaten Nganjuk, 2020.

[3] N. Ratri dan Y. Helmy, “Lima Daerah Ini Punya Angka Kecelakaan Tertinggi di Jatim, Kota Malang Nomor Berapa?, MalangTimes, Malang, 2017.

[4] Satlantas, “Data Anatomi Januari 2018-Oktober 2020," Satlantas Kabupaten Nganjuk, Nganjuk, 2020.

[5] H. Harirforoush, L. Bellalite dan G. B. Benie, "Spatial and Temporal Analysis of Seasonal Traffic Accidents," American Journal of Traffic and Transportation Engineering, pp. 7-16, 2019.

[6] Y. Zhang, H. Lu dan W. Qu, "Geographical Detection of Traffic Accident Spatial Stratified Heterogeneity and Influence Factors," International Journal of Environment Research and Public Health, 2020.

[7] A. Baddeley, G. Nair, S. Rakshit, G. McSwiggan dan T. M. Davies, "Analysing point patterns on networks - A review," Spatial Statistics, 2020.

[8] A. Choiruddin, J.-F. Coeurjolly dan F. Letué, “Convex and non-convex regularization methods for spatial point processes intensity estimation," Electronic journal of statistics, vol. 12(1), pp. 1210-1255, 2018.

[9] A. Baddeley, E. Rubak dan R. Turner, Spatial point patterns : methodology and applications with R, CRC press, 2015.

[10] Q. W. Ang, A. Baddeley dan G. Nair, "Geometrically Corrected Second Order Analysis of Events on a linear Network with Applications to Ecology and Criminology," Scandinavian Journal of Statistics, 2011. 
[11] A. Choiruddin, Aisah, F. Trisnisa dan N. Iriawan, “Quantifying the Effect of Geological Factors on Distribution of Earthquake Occurrences by Inhomogeneous Cox Processes," Pure and Applied Geophysics, vol. 178(5), pp. 1579-1592, 2021.

[12] A. Choiruddin, J.-F. Coeurjolly dan R. Waagepetersen, "Information criteria for inhomogeneous spatial point processes," Australian \& New Zealand Journal of Statistics, vol. 63(1), pp. 119-143, 2021.

[13] A. Choiruddin, J.-F. Coeurjolly dan R. Waagepetersen, "Regularized estimation for highly multivariate log Gaussian Cox processes," Statistics and Computing, vol. 30(3), pp. 649-662, 2020. 